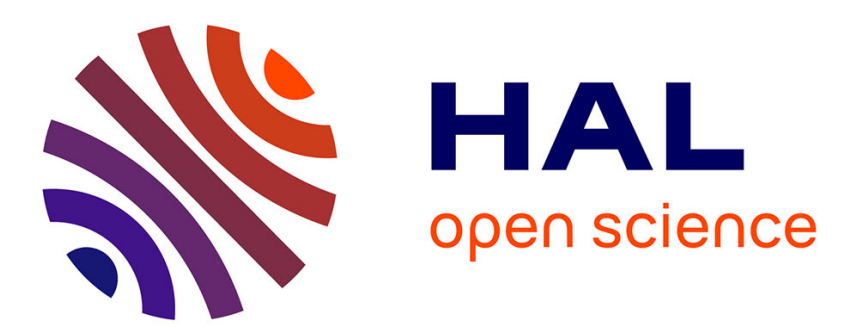

\title{
Rotational relaxation model for CO-N2. Prediction of CARS profiles and comparison with experiment
}

\author{
A. Roblin, J. Bonamy, D. Robert, M. . Lefebvre, M. Péalat
}

\section{To cite this version:}

A. Roblin, J. Bonamy, D. Robert, M. . Lefebvre, M. Péalat. Rotational relaxation model for CO-N2. Prediction of CARS profiles and comparison with experiment. Journal de Physique II, 1992, 2 (3), pp.285-294. 10.1051/jp2:1992134 . jpa-00247632

\section{HAL Id: jpa-00247632 https://hal.science/jpa-00247632}

Submitted on 1 Jan 1992

HAL is a multi-disciplinary open access archive for the deposit and dissemination of scientific research documents, whether they are published or not. The documents may come from teaching and research institutions in France or abroad, or from public or private research centers.
L'archive ouverte pluridisciplinaire HAL, est destinée au dépôt et à la diffusion de documents scientifiques de niveau recherche, publiés ou non, émanant des établissements d'enseignement et de recherche français ou étrangers, des laboratoires publics ou privés. 
Classification

Physics Abstracts

$33.20-33.70-34.20$

\title{
Rotational relaxation model for $\mathrm{CO}-\mathrm{N}_{2}$. Prediction of CARS profiles and comparison with experiment
}

\author{
A. Roblin $\left({ }^{1, *}\right)$, J. Bonamy $\left({ }^{2}\right)$, D. Robert $\left({ }^{2}\right)$, M. Lefebvre $\left({ }^{3}\right)$ and M. Péalat $\left({ }^{3}\right)$ \\ (1) Faculté des Sciences (**), B.P. 118, 76134 Mont Saint Aignan Cedex, France \\ (2) Université de Franche-Comté, Laboratoire de Physique Moléculaire (***), La Bouloie, \\ 25030 Besançon Cedex, France \\ (3) Office National d'Etudes et de Recherches Aérospatiales, B.P. 72, 92322 Châtillon Cedex, \\ France
}

(Received 28 May 1991, revised 22 November 1991, accepted 26 November 1991)

\begin{abstract}
Résumé. - Le spectre de diffusion Raman Anti-Stokes Cohérente (DRASC) de la branche Q fondamentale de $\mathrm{CO}$ pur et perturbé par $\mathrm{N}_{2}$ a été enregistré à température ordinaire entre 1 et 20 atmosphères. Les coefficients d'élargissement collisionnel ont été calculés à partir d'une approche semi-classique. Les taux de transferts totationnels d'état-à-état ont été calculés à l'aide d'un modèle relaxationnel par inversion des coefficients d'élargissement. Les prédictions de ce modèle sont en accord satisfaisant avec les spectres DRASC expérimentaux.

Abstract. - The CO $v=1 \leftarrow 0$ Q-branch perturbed by $\mathrm{CO}$ and $\mathrm{N}_{2}$ has been recorded using Coherent Anti-Stokes Raman Spectroscopy (CARS) at room temperature between 1 and 20 atmosphere. Collisional broadening coefficients calculated with a semiclassical theory have been inverted to obtain the rotationally inelastic state-to-state rate constants, using the Modified Energy Gap (MEG) law. The resulting theoretical collisionally narrowed Q-branch profiles are in agreement with the experimental spectra.
\end{abstract}

\section{Introduction.}

During the last several years, considerable effort has been devoted to non-linear Raman studies of nitrogen at high pressure and temperature. Most of this work has been motivated by interest in temperature measurements in flames. First, the linewidths and line shifts of the isolated Q-branch lines have been measured with high accuracy $[1,2]$ by using stimulated Raman spectroscopy (SRS). Then, the drastic pressure induced narrowing of the Q-branch bandshape has been analyzed in terms of rotational relaxation models $[3,4]$. By successive improvements, these models are now able to predict accurately the SRS and CARS profiles

(*) Permanent address: Office National d'Etudes et de Recherches Aérospatiales, B.P. 72, 92322 Châtillon Cedex, France.

(**) URA CNRS $\mathrm{N}^{\circ} 230$.

(***) URA CNRS $\mathrm{N}^{\circ} 772$. 
[5] of pure $\mathrm{N}_{2}$ in a wide range of pressure and temperature (up to 100 bar and $1500 \mathrm{~K}$ ). For practical applications in flames, additional studies $[6,8]$ including relaxation of nitrogen by minor components such as $\mathrm{CO}_{2}$ and $\mathrm{H}_{2} \mathrm{O}$ have also been performed. A $5 \%$ accuracy for temperature measurements appears now highly feasible [9].

The success of these relaxation models for predicting the non-linear Raman profiles and the need for concentration measurements of other gas species $\left(\mathrm{H}_{2}, \mathrm{CO}, \mathrm{CO}_{2}\right.$, . ) have suggested further work in this field. Among them, the $\mathrm{CO}$ molecule is of interest due to its spectroscopic similarity to $\mathrm{N}_{2}$ and its role in pollution. Recent SRS measurements and prediction of CO Raman Q-branch in the temperature range 400-1 $500 \mathrm{~K}$ have been achieved by Rosasco et al. [10]. As with pure $\mathrm{N}_{2}$, an efficient rotational relaxation model yields an accurate description of the CO Q-branch. Other relaxation models have been analyzed [11] to attain a more physical understanding of the line coupling mechanisms leading to the collapse of the Qbranch, in connection with the weak heteronuclear character of the $\mathrm{CO}$ molecule.

The aim of the present work is to study the rotational relaxation of CO perturbed by $\mathrm{N}_{2}$ and to compare the resulting theoretical CARS profile with experimental spectra. In order to show the general consistency of the relaxation models for both $\mathrm{CO}-\mathrm{CO}$ and $\mathrm{CO}-\mathrm{N}_{2}, \mathrm{CARS}$ spectra for the pure $\mathrm{CO}$ Q-branch have been also recorded. These measurements complement the previous SRS analysis [10]. Apart from the physical interest in studies of $\mathrm{CO}-\mathrm{N}_{2}$ collisional induced transfers, the predominance of nitrogen in most of combusting media makes such a molecular pair of particular practical importance.

Semiclassical calculations of line broadening coefficients are presented in section 2 , and compared with available experimental data. Using this reliable set of calculated line broadening coefficients in a wide temperature range, a rotational relaxation gap law is developed for $\mathrm{CO}-\mathrm{N}_{2}$ (Sect. 3). Predictions of this relaxation model are compared with CARS measurements in section 4. Discussion and concluding remarks are given in section 5.

\section{Semiclassical Q-line broadening calculations.}

At high temperature, the perturbative semiclassical approaches become unrealistic because both kinetic and potential effects of close collisions must be accounted for. A convenient approach has been proposed ten years ago by two of the present authors [12]. Many applications [12-18] have largely proved its accuracy for various molecular systems in a wide temperature range. The anisotropic intermolecular potential used in this formulation of molecular line broadening and line shifting, is an atom-atom pairwise additive Lennard-Jones potential supplemented by dipolar and quadrupolar interactions. The molecular parameters for $\mathrm{CO}$ and $\mathrm{N}_{2}$ are given in table $\mathrm{I}$. For calculation of trajectories, which requires the knowledge of the CO- $\mathrm{N}_{2}$ isotropic potential, a Lennard-Jones is chosen. Its characteristic parameters are fitted to spherically averaged atom-atom potential $\left(\varepsilon_{\mathrm{CO}_{-} \mathrm{N}_{2}}=98.5 \mathrm{~K}\right.$ and $\sigma_{{\mathrm{CO}-\mathrm{N}_{2}}}=3.78 \AA$ ). The calculated Raman Q-line broadening coefficients (up to $2000 \mathrm{~K}$ ) are given in table II. In order to test the model and our procedure, we have calculated the infrared linewidth at room temperature. Comparison with available experimental data [19-21] shows good consistency (Fig. 1), which is also expected at higher temperature due to the basic assumptions of the semiclassical model. Similar calculations by Looney and Rosasco [11, 18] for pure $\mathrm{CO}$, using the semiclassical formulation of reference [12], have also led to excellent agreement with both infrared R-branch and Raman Q-branch data over a wide range of rotational quantum numbers and temperatures (up to $J=30$ and $T=1500 \mathrm{~K}$ ).

The present calculations and the results of Looney et al. $[11,18]$ clearly show that the accuracy of the semiclassical model of reference [12] for $\mathrm{CO}-\mathrm{CO}$ and $\mathrm{CO}-\mathrm{N}_{2}$ is of the same order as the experimental one $(\leqslant 5 \%)$. As a consequence, exhaustive measurements of line broadening coefficients for the molecular pair CO- $\mathrm{N}_{2}$, as performed by Rosasco et al. [10] for 
Table I. - Molecular parameters for $\mathrm{CO}-\mathrm{N}_{2}$ line broadening calculations [a] STOGRYN D. E. and Stogryn A. P., Mol. Phys. 11 (1966) 371. [b] MEerks W. L., DE LEeUW F. H. and Dymanus A., Chem. Phys. 22 (1977) 319. [c] Mulder F., van Duk G. and van DeR Avolrd A., Ad. Mol. Phys. 39 (1980) 407. [d] Oobatake D. and Ool T., Prog. Theor. Phys. 48 (1972) 2132. [e] The $\varepsilon$ and $\sigma$ coefficients of the angle-independent potential have been numerically determined from the isotropic part of the atom-atom potential.

\begin{tabular}{|l|c|c|}
\hline Parameter & Value & Reference \\
\hline$\mu_{\mathrm{CO}}(\mathrm{D})$ & 0.112 & {$[\mathrm{a}]$} \\
$\mathrm{Q}_{\mathrm{CO}}(\mathrm{D} . \AA)$ & $-1.65 /-1.85^{*}$ & {$[\mathrm{a}, \mathrm{b}]$} \\
$\mathrm{Q}_{\mathrm{N}_{2}}(\mathrm{D} . \AA)$ & $-1.30 /-1.50^{*}$ & {$[\mathrm{a}, \mathrm{c}]$} \\
$e_{\mathrm{C}-\mathrm{N}}\left(10^{-10} \mathrm{erg} \AA^{6}\right)$ & 0.33 & {$[\mathrm{~d}]$} \\
$e_{\mathrm{O}-\mathrm{N}}\left(10^{-10} \mathrm{erg} \AA^{6}\right)$ & 0.26 & {$[\mathrm{~d}]$} \\
$d_{\mathrm{C}-\mathrm{N}}\left(10^{-7} \mathrm{erg} \AA^{12}\right)$ & 0.55 & {$[\mathrm{~d}]$} \\
$d_{\mathrm{O}-\mathrm{N}}\left(10^{-7} \mathrm{erg} \AA^{12}\right)$ & 0.30 & {$[\mathrm{~d}]$} \\
$\left|r_{10}\right|(\AA)$ & 0.48 & {$[\mathrm{~d}]$} \\
$\left|r_{1 \mathrm{c}}\right|(\AA)$ & 0.64 & {$[\mathrm{~d}]$} \\
$\left|r_{2 \mathrm{~N}}\right|(\AA)$ & 0.55 & {$[\mathrm{~d}]$} \\
$\varepsilon_{\mathrm{CO}-\mathrm{N}_{2}}(\mathrm{~K})$ & 98.5 & {$[\mathrm{e}]$} \\
$\sigma_{\mathrm{CO}-\mathrm{N}_{2}}(\AA)$ & 3.78 & {$[\mathrm{e}]$} \\
\hline
\end{tabular}

* These values have been retained for the $\mathrm{CO}-\mathrm{N}_{2}$ calculations.

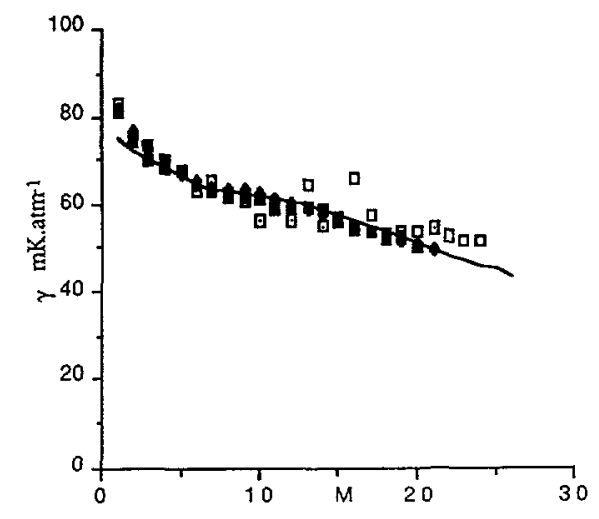

Fig. 1. - Comparison between theoretical (-) and experimental Infrared CO- $\mathrm{N}_{2}$ linewidths at room

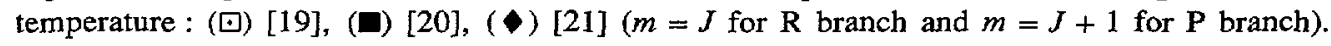

pure $\mathrm{CO}$, are not required. The semiclassical values of table II can be used with confidence. The rotational relaxation model needed to account for the strong line mixing which appears at high pressure, will be developed now starting from these values as basic data.

\section{Rotational relaxation model.}

Among several relaxation models proposed to account for line mixing induced by collisions, two of them have given satisfactory agreement [22] : the energy corrected sudden (ECS) and 
Table II. - Calculated CO-N $\mathrm{N}_{2}$ line-broadening coefficients $\left(\gamma\right.$ in $\left.10^{-3} \mathrm{~cm}^{-1} \mathrm{~atm}^{-1}\right)$.

\begin{tabular}{|c|c|c|c|c|c|c|c|}
\hline$J$ & $T=295 \mathrm{~K}$ & $T=404 \mathrm{~K}$ & $T=504 \mathrm{~K}$ & $T=701 \mathrm{~K}$ & $T=1004 \mathrm{~K}$ & $T=1504 \mathrm{~K}$ & $T=2000 \mathrm{~K}$ \\
\hline 0 & 76.2 & 58.8 & 49.2 & 38.0 & 29.1 & 21.9 & 18.2 \\
1 & 70.5 & 54.6 & 45.9 & 35.7 & 27.6 & 20.9 & 17.4 \\
2 & 71.1 & 55.5 & 46.7 & 36.5 & 28.1 & 21.3 & 17.7 \\
3 & 69.6 & 54.8 & 46.4 & 36.4 & 28.2 & 21.4 & 17.7 \\
4 & 67.7 & 53.6 & 45.7 & 36.1 & 28.1 & 21.4 & 17.8 \\
5 & 65.9 & 52.4 & 44.8 & 35.7 & 27.9 & 21.4 & 17.8 \\
6 & 64.6 & 51.3 & 43.9 & 35.1 & 27.7 & 21.3 & 17.7 \\
7 & 63.9 & 50.5 & 43.2 & 34.6 & 27.4 & 21.2 & 17.7 \\
8 & 63.5 & 50.1 & 42.7 & 34.2 & 27.1 & 21.0 & 17.6 \\
9 & 63.1 & 49.8 & 42.4 & 33.9 & 26.8 & 20.9 & 17.5 \\
10 & 62.6 & 49.5 & 42.2 & 33.6 & 26.6 & 20.7 & 17.5 \\
11 & 62.0 & 49.3 & 42.1 & 33.5 & 26.5 & 20.6 & 17.4 \\
12 & 61.1 & 48.9 & 41.8 & 33.4 & 26.4 & 20.5 & 17.3 \\
13 & 60.1 & 48.4 & 41.6 & 33.2 & 26.3 & 20.4 & 17.2 \\
14 & 58.9 & 47.8 & 41.2 & 33.1 & 26.2 & 20.3 & 17.1 \\
15 & 57.6 & 47.1 & 40.8 & 32.9 & 26.1 & 20.3 & 17.1 \\
16 & 56.3 & 46.4 & 40.4 & 32.7 & 26.0 & 20.2 & 17.0 \\
17 & 54.9 & 45.6 & 39.9 & 32.5 & 25.9 & 20.2 & 17.0 \\
18 & 53.4 & 44.7 & 39.3 & 32.2 & 25.8 & 20.1 & 16.9 \\
19 & 52.5 & 44.0 & 38.8 & 31.9 & 25.7 & 20.1 & 16.9 \\
20 & 51.3 & 43.1 & 38.1 & 31.6 & 25.5 & 20.0 & 16.9 \\
21 & 49.3 & 41.9 & 37.3 & 31.2 & 25.4 & 19.9 & 16.8 \\
22 & 48.1 & 41.0 & 36.6 & 30.8 & 25.2 & 19.9 & 16.8 \\
23 & 46.7 & 40.1 & 36.0 & 30.4 & 25.0 & 19.8 & 16.7 \\
24 & 45.7 & 39.2 & 35.3 & 30.0 & 24.8 & 19.7 & 16.7 \\
25 & 44.1 & 38.1 & 34.4 & 29.5 & 24.5 & 19.6 & 16.6 \\
\hline
\end{tabular}

the phenomenological model called modified energy gap (MEG) law. The ECS model [23] has been found very convenient for pure $\mathrm{N}_{2}$ [4]. In this ECS model [4, 11, 24], the basis rates are modeled through either a polynomial [4] or an exponential law [11, 24]. The use of a polynomial-exponential law (ECS-EP) leads to significant improvements to predict accurate collapsed $Q$ branch at high density [25]. Unfortunately, the so-calculated ECS-EP relaxation matrix exhibits unphysical features [26]. Convenient modifications have been proposed which need further accurate tests.

Concerning pure $\mathrm{CO}$, the recent analysis of Looney et al. [11] has shown that the ECS scaling law gives a reasonably good description of $J$ and $T$ linewidths dependence, but overestimates the narrowing effect. So, we have retained here the MEG law [27] which gives a correct description [11] of the pressure induced SRS spectral modifications for CO-CO. This exponential gap law for the rotational transfer rate is modified by a correcting factor dependent on the rotational energy $E_{J}[27]$

$$
W_{J J^{\prime}}^{\mathrm{MEG}}(T)=-A(T)\left(\frac{1+2 E_{J} / k T \Delta}{1+2 E_{J} / k T}\right)^{2} \exp \left(-\frac{\beta\left(E_{J^{\prime}}-E_{J}\right)}{k T}\right)
$$


Equation (1) holds for upward rotational transitions from $J$ to $J^{\prime}$, the downward ones being deduced through the detailed balance principle. The numerical factor 2 appearing in the preexponential term is estimated as in reference [28]. $A(T), \Delta$ and $\beta$ are fitted to the calculated line broadening coefficients $\gamma_{J}$ of table II through the conservation of the total rotational population

$$
\gamma_{J}=-\sum_{J^{\prime} \neq J} W_{J J^{x}}
$$

The sum is taken over all $J$-rotational quantum numbers in spite of the «almost homonuclear $\gg$ character of $\mathrm{CO}$, as discussed by Looney et al. and suggested from ab initio calculations [24] for pure CO. The optimization procedure used to determine $A(T), \Delta$ and $\beta$ has been described in reference [4]. Since the broadening coefficients are calculated values, a uniform uncertainty of $5 \%$ has been introduced in the weighting factor. Two successive steps are followed. First, the three parameters are fitted for each of the seven temperatures reported in table II. The resulting values expressed in reduced units are gathered in figure 2. It appears that $\Delta$ and $\beta$ parameters exhibit a residual temperature dependence for

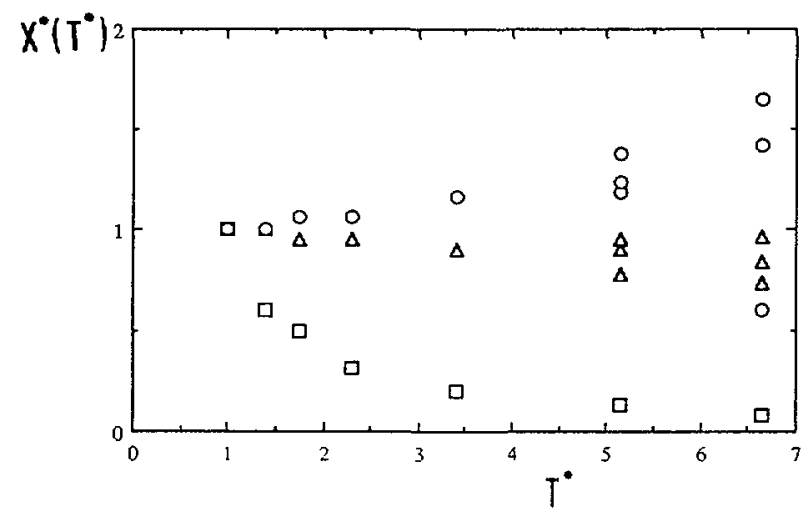

Fig. 2. - Reduced fitting parameters for the CO-N $\mathrm{N}_{2}$ MEG law $\left(X^{*}\left(T^{*}\right)=X\left(T^{*}\right) / X(1)\right)$ versus $T^{*}=T / 295 \mathrm{~K}\left(X^{*} \equiv\left\{A^{*} \cdot(\square) ; \Delta^{*} \cdot(\Delta) ; \beta^{*} \cdot(0)\right\}\right)$.

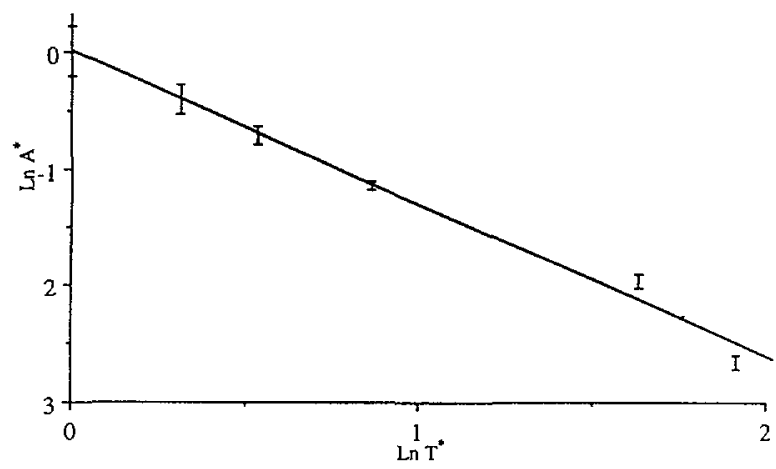

Fig. 3. - Temperature dependence of the amplitude coefficient for the CO-N 2 MEG law (in logarithmic scale) : I : optimized value for a given temperature; $(\longrightarrow)$ : fit by equation (3) with $A(295 \mathrm{~K})=12.4 \mathrm{mK} \cdot$ atm $^{-1}$ and $N=1.27$. 
$T>750 \mathrm{~K}$. Secondly, choosing for $\Delta$ and $\beta$ their average value over the temperature range $300-750 \mathrm{~K}(\Delta=1.11 \pm 0.04$ and $\beta=1.56 \pm 0.05)$, it is then possible to reanalyze the temperature dependence of $A(T)$ (Fig. 3) which can be approximated by the simple usual form

$$
A(T)=A(295 \mathrm{~K})\left[\frac{295}{T}\right]^{N}
$$

with $A(295 \mathrm{~K})=12.4 \pm 0.5 \mathrm{mK} \mathrm{atm}^{-1}, N=1.27 \pm 0.04$. This MEG law gives an excellent fit of the semiclassical linewidths over a wide range of temperature (Fig. 4). Figure 5 shows rotationally inelastic state-to-state rates as a function of initial and final quantum numbers. Inherently to the MEG model, such rate dependences on $J$ and $J^{\prime}$ do not exhibit a

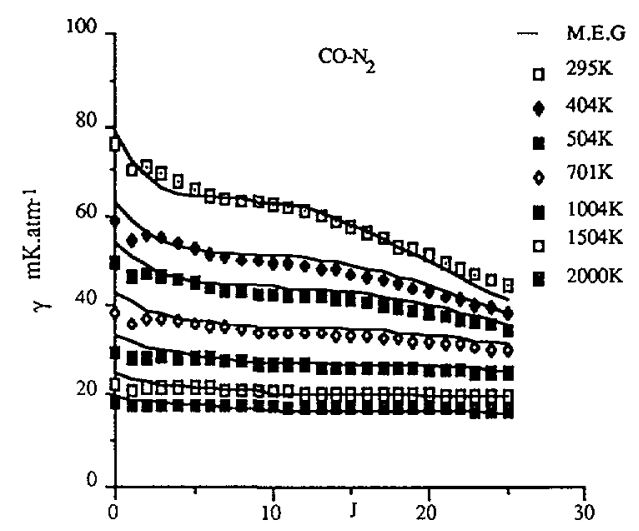

Fig. 4. - CO- $\mathrm{N}_{2}$ pressure broadening coefficients versus $J$ at each of the calculated temperatures. The curves represent the $\gamma_{J}$ values derived from the best fit MEG law [Eqs. (1)-(3)].

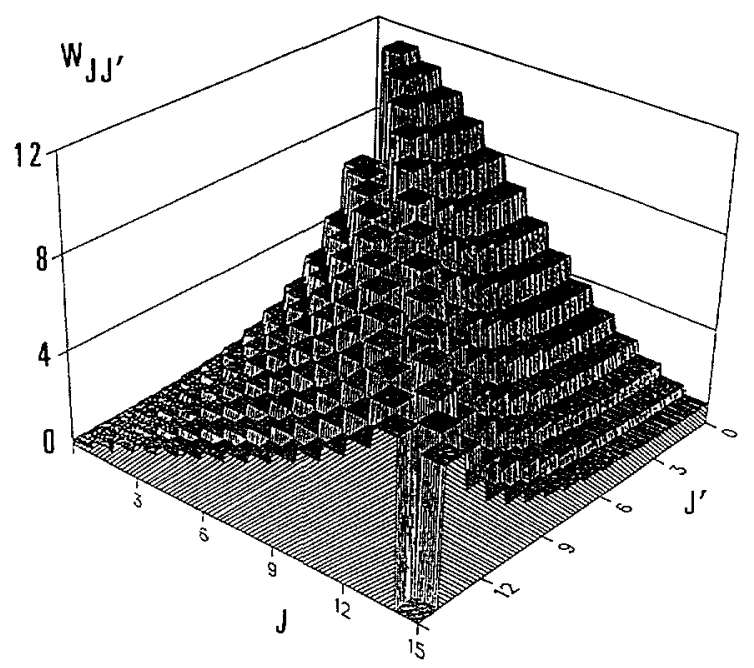

Fig. 5. - Off-diagonal elements $W_{J J^{\prime}}$ (in $\mathrm{mK} \cdot \mathrm{atm}^{-1}$ ) of the relaxation matrix for the CO- $\mathrm{N}_{2} \mathrm{MEG}$ law at $300 \mathrm{~K}$. 
predominance of quadrupolar forces which would enhance even $\left|J^{\prime}-J\right|$ jumps. Let us mention that an alternative relaxation model, named statistical polynomial energy-gap (SPEG) has been shown to be consistent in reproducing the pure CO data with only even jumps [11].

However, it has been shown in different studies [4, 11, 27] that CARS spectra are not significantly dependent on the details of the relaxation matrix.

\section{CARS measurements and comparison with MEG prediction.}

The CO CARS spectra were recorded with a CARS unit, the description of which can be found in references [29] and [30]. A single mode ND : YAG laser with two $7 \mathrm{~mm}$ diameter amplifiers and one type II KD* $\mathrm{P}$ doubler delivers $155 \mathrm{~mJ}$ at $532 \mathrm{~nm}$ (maximum energy $200 \mathrm{~mJ}$ at full power) in $10 \mathrm{~ns}$ pulses at $5 \mathrm{~Hz}$. Part of the $155 \mathrm{~mJ}$ is used to pump a tunable dye laser $\left(\omega_{s}\right.$ Stokes frequency) composed of oscillator and one amplifier at $\omega_{s}$ frequency whereas the remainder is used as the $\omega_{\mathrm{p}}$ pump beam. The net energies at the output of the CARS optical bench are $70 \mathrm{~mJ}$ and $3 \mathrm{~mJ}$ for the $532 \mathrm{~nm}$ and Stokes beams respectively. Planar BOXCARS is used and the non-resonant background cancellation is performed by using the conventional $60^{\circ}$ polarisation orientation for the Stokes beam and for the analysis of the antiStokes beam. The CARS beams are focussed using a $500 \mathrm{~mm}$ focal length achromat, yielding a $16 \mathrm{~mm}$ long, $100 \mu \mathrm{m}$ diameter probe volume. Reference and sample CARS spectra are dispersed in separate spectrometers and detected by means of two photomultipliers. The sample signal is divided by the reference one and the ratio is averaged for five laser shots at each fixed Stokes position.

The spectra are scanned by step of $0.005 \AA$. Previously to the experiment, a $0.66 \mathrm{~Pa}$ pure $\mathrm{CO}$ spectrum is recorded. Fitting that experimental spectrum yields the Stokes spectral shape which is approximately Gaussian (half-width at $1 / e: \gamma=0.045 \pm 0.010 \mathrm{~cm}^{-1}$ ) and the calibration of the scanning mechanism.

CARS profile is calculated from the square modulus of the third order susceptibility $\chi^{(3)}$ Its resonant part $\chi_{\mathrm{r}}^{(3)}$ may be expressed as [31]

$$
\chi_{\mathrm{r}}^{(3)}=\frac{i N}{h} \sum_{J} \alpha_{J} \sum_{J^{\prime}} \alpha_{J^{\prime}} \Delta \rho_{J^{\prime}}\left[G^{-1}\right]_{J^{\prime}}
$$

where $N$ is the number density, $\alpha_{J}$ the isotropic polarizability, $\Delta \rho_{J^{\prime}}$ denotes the population difference between the states involved and the $G$-matrix is given in terms of the $W$-relaxation matrix by

$$
G_{J J^{\prime}}=i\left(\omega_{\mathrm{p}}-\omega_{\mathrm{s}}-\omega_{J}-i \gamma_{J}\right) \delta_{J J^{\prime}}+W_{J J^{\prime}}\left(1-\delta_{J J^{\prime}}\right)
$$

where $\omega_{\mathrm{p}}$ and $\omega_{\mathrm{s}}$ are the frequencies of the pump and Stokes laser respectively, $\gamma_{J}$ is the half width at half maximum (HWHM) of the isolated $\mathrm{Q}(J)$-line at frequency $\omega_{J}$, and $W_{J J}$, the off-diagonal elements of the relaxation matrix. In equation (5) the pressureinduced line shifts have been omitted as a small, overall shift of the whole Q-branch spectrum. The relaxation matrix is calculated from the MEG model given by equations (1) and (3) with the fitting parameters $A(295 \mathrm{~K}), N, \Delta$ and $\beta$ given in the preceding section.

The comparison between theoretical and experimental $Q$-branch CARS spectra is given in figure $6 a$ at atmospheric pressure and $6 b$ at a higher pressure corresponding to collapsed $Q$ branch. The calculation has been performed with the following relaxation matrix

$$
\left\{W_{J J^{\prime}}\right\}=x_{\mathrm{N}_{2}}\left\{W_{J J^{\prime}}\right\}_{\mathrm{CO} \cdot \mathrm{N}_{2}}+x_{\mathrm{CO}}\left\{W_{J J^{\prime}}\right\}_{\mathrm{CO}-\mathrm{CO}}
$$


a)

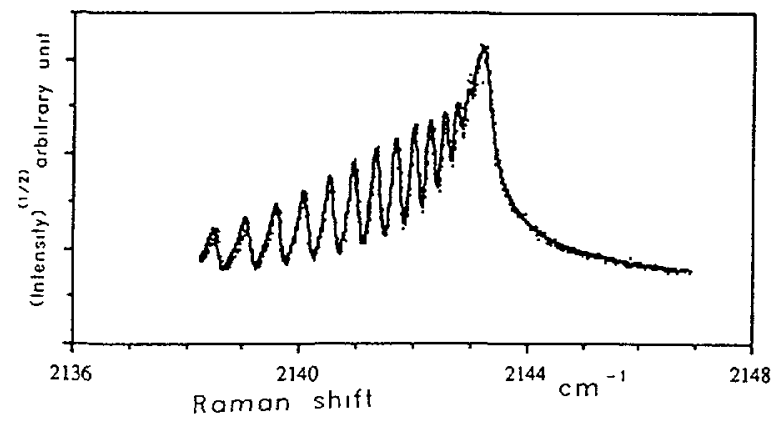

b)

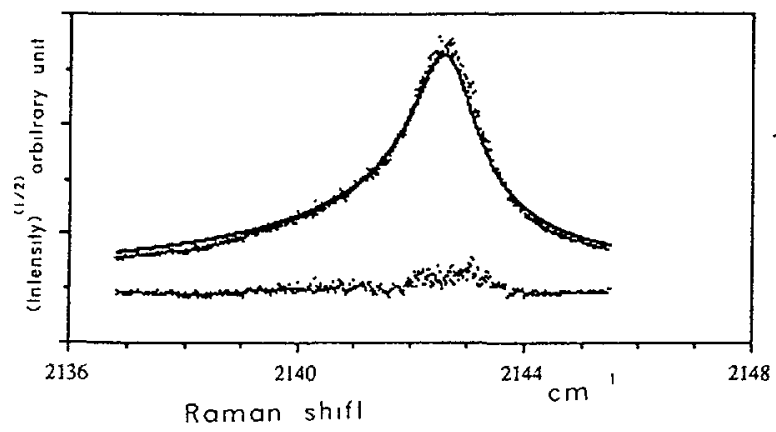

Fig. 6. - The MEG law prediction of the $\mathrm{CO}-\mathrm{N}_{2}$ Q-branch spectrum (solid line) compared with experimental spectra at (a) $0.98 \mathrm{~atm}$ and (b) $19.63 \mathrm{~atm}$ at $T=300 \mathrm{~K}$. This comparison assumes equal square root integrated intensities. Residual errors are also shown.

a)

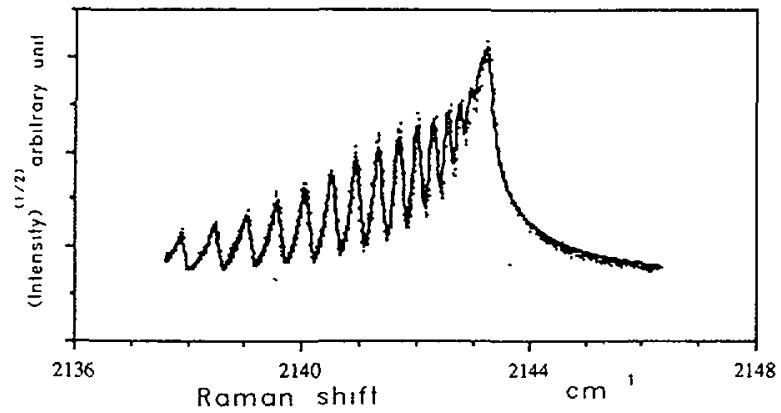

b)

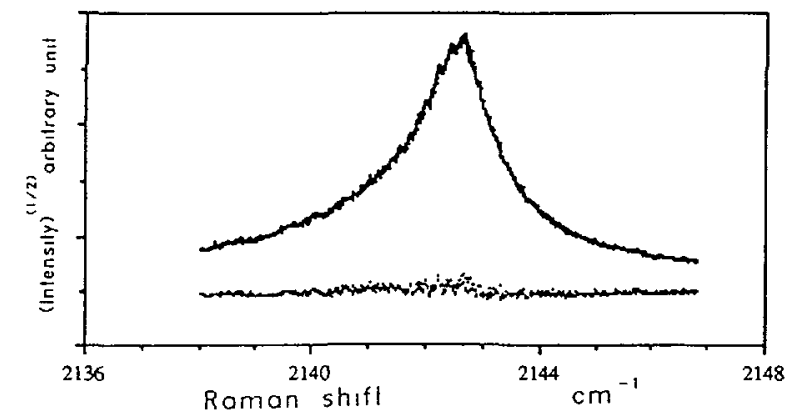

Fig. 7. - The MEG law prediction of the CO-CO Q-branch spectrum (solid line) compared with experimental spectra at (a) $1.01 \mathrm{~atm}$ and (b) $19.70 \mathrm{~atm}$ at $T=300 \mathrm{~K}$; (same conditions as in Figs. 6). 
where $x_{\mathrm{N}_{2}}$ and $x_{\mathrm{CO}}$ are the molar concentration of each species $\left(x_{\mathrm{N}_{2}}=90 \%\right.$ and $x_{\mathrm{CO}}=10 \%$ for the present CARS experiments). At this stage, the knowledge of the pure CO relaxation matrix $\left\{W_{J J^{\prime}}\right\}_{\mathrm{CO}-\mathrm{CO}}$ is also needed. A similar calculation for $\mathrm{CO}-\mathrm{CO}$ as for $\mathrm{CO}-\mathrm{N}_{2}$ has thus been performed [32].

CARS spectra are also given for pure CO (Figs. 7) to allow a significant comparison with the $\mathrm{CO}-\mathrm{N}_{2}$ mixture.

\section{Discussion and concluding remarks.}

The agreement between MEG law predictions and CARS experiments is quite satisfactory for the highest pressures considered here (Figs. $6 \mathrm{~b}$ and $7 \mathrm{~b}$ ). For pure $\mathrm{CO}$, the calculated profile lies inside the experimental uncertainties. For CO- $\mathrm{N}_{2}$, the residuals show a few discrepancies. Apart from the mixture effect which is accounted for in the calculated profile through the usual simple law (cf. Eq. (6)) and may also induce additional experimental uncertainties, no other reason can be a priori invoked to interpret these discrepancies. The molecular parameters for $\mathrm{N}_{2}$ are close to those of $\mathrm{CO}$ leading to a similar consistency between calculated and experimental line broadening coefficients for pure $\mathrm{CO}$ [18] and for the $\mathrm{CO}-\mathrm{N}_{2}$ mixture.

At atmospheric pressure, for which the CARS spectra are almost resolved, the residuals have not been given in figures $6 \mathrm{a}$ and $7 \mathrm{a}$, due to their unsignificant meaning. Indeed, the spectral resolution (14.5 mK, cf. [32]) which is about $25 \%$ of the line broadening coefficient at room temperature, does not allow such a quantitative comparison between calculated and experimental CARS spectra.

For optical diagnostics, which is the aim of the present study, one may consider that the MEG model allows an accurate quantitative description of the experimental CARS spectra. Of course, from a fundamental point of view, several basic problems have to be explored further. In addition to the above mentioned mixture effects, the role of the dominant intermolecular forces symmetry should be analyzed. Such an analysis would require available measured state-to-state rotational rates for pure $\mathrm{CO}$ and for $\mathrm{CO}-\mathrm{N}_{2}$, as recently performed for $\mathrm{H}_{2}, \mathrm{HD}$ and $\mathrm{N}_{2}$ [33-35]. The relaxation models themselves should also be improved [26] by including properly such symmetry properties.

\section{References}

[1] Lavorel B., Millot B., Saint-Loup R., Wenger C., Berger H., Sala J. P., Bonamy J. and RoBert D., J. Phys. France 47 (1986) 417.

[2] Rahn L. A. and Palmer R. E., J. Opt. Soc. Am. B 3 (1986) 1164.

[3] Rahn L. A., Palmer R. E., Koszykowski M. L. and Greenhalgh D. A., Chem. Phys. Lett. 133 (1987) 513.

[4] Bonamy L., Bonamy J., Robert D., Lavorel B., Saint-loup R., Chaux R., Santos J. and Berger H., J. Chem. Phys. 89 (1988) 5568.

[5] Greenhalgh D. A., in Advances in non-linear spectroscopy, 15 R. J. H. Clark and R. E. Hester Eds. (Wiley, New York, 1988).

[6] Bonamy J., Robert D., Hartmann J. M., Gonze M. L., Saint-Loup R. and Berger H., $J$. Chem. Phys. 91 (1989) 5916.

[7] Gonze M. L., Saint-loup R., Santos J., Lavorel B., Chaux R., Millot G., Berger H., Bonamy L., Bonamy J, and Robert D., Chem. Phys. 148 (1990) 417.

[8] Bonamy J., Bonamy L., Robert D., Gonze M. L., Millot G., Lavorel B. and Berger H., $J$. Chem. Phys. 94 (1991) 6584. 
[9] Woyde M. and Stricker W., Appl. Phys. B 50 (1990) 519;

STRICKER W. and WOYDE M., Proc. Joint Meeting German and Italian Sections Combustion Institute, Ravello (Italy) (1989) p. 11.

[10] Rosasco G. J., Rahn L. A., Hurst W. S., Palmer R. E. and Dohne S. M., J. Chem. Phys. 90 (1989) 4059.

[11] Looney J. P., Rosasco G. J., Rahn L. A., Hurst W. S. and Hahn J. W., Chem. Phys. Lett. 161 (1989) 232.

[12] ROBERT D. and Bonamy J., J. Phys. France 40 (1979) 923.

[13] Bonamy J., ROBerT D. and Boulet C., J. Quant. Spectrosc. Radiat. Transfer 31 (1984) 23.

[14] Le Doucen R., Cousin R., Boulet C. and HenRy A., Appl. Opt. 24 (1985) 897.

[15] Lacome N., Levy A. and Guelachvili G., Appl. Opt. 23 (1984) 425.

[16] Margottin-Maclou M., Dahoo P., Henry A., Valentin A. and Henry L., J. Mol. Spectrosc. 131 (1988) 21.

[17] Hartmann J. M., Rosenmann L., Perrin M. Y. and Taine J., Appl. Opt. 27 (1988) 3063.

[18] Looney J. P. and Rosasco G. J., J. Chem. Phys. 95 (1991) 2379.

[19] Varghese P. L. and Hanson R. K., J. Quant. Spectrosc. Radiat. Transfer 24 (1979) 479.

[20] Bouanich J. P., J. Quant. Spectrosc. Radiat. Transfer 13 (1973) 953 ;

BOUANICH J. P. and BRODBECK C., ibid. 13 (1973) 1.

[21] Nakazawa T. and Tanaka M., J. Quant. Spectrosc. Radiat. Transfer 28 (1982) 409.

[22] Robert D., Vibrat. Spectra Struct. B 17 (1989) 57.

[23] Depristo A. E., Augustin S. D., Ramaswamy R. and Rabitz H., J. Chem. Phys. 71 (1979) 850.

[24] Belbruno J. J., Gelfand J. and Rabitz H., J. Chem. Phys. 78 (1983) 3990 (see Ref. [10c]).

[25] Mrllot G., J. Chem. Phys. 93 (1990) 8001.

[26] Bonamy L., Thuet J. M., Bonamy J. and Robert D., J. Chem. Phys. 95 (1991) 3361.

[27] Koszykowski M. L., Rahn L. A., Palmer R. E. and Coltrin M. E., J. Phys. Chem. 91 (1987) 41.

[28] Lavorel B., Millot G., Saint-Loup R. and Berger H., Bonamy L., Bonamy J. and Robert D., J. Chem. Phys. 93 (1990) 2176.

[29] Papineau N. and Pealat M., J. Chem. Phys. 79 (1983) 5758.

[30] Pealat M., Taran J. P. and Moya F., Opt. Laser Technol. 1221 (1980).

[31] Hall R. J., Verdieck J. F. and Eckbreth A. C., Opt. Commun. 35 (1980) 69.

[32] ROBLIN A., Thèse, Rouen France (1990).

[33] Chandler D. W. and Farrow R. L., J. Chem. Phys. 85 (1986) 810.

[34] Farrow R. L. and Chandler D. W., J. Chem. Phys. 89 (1988) 1994.

[35] SITZ G. O. and Farrow R. L., J. Chem. Phys. 93 (1990) 7883. 